\title{
Place of death in children and young people with cancer and implications for end of life care: a population-based study in England, 1993-2014
}

Wei Gao $^{1 *}$ D, Julia Verne ${ }^{2}$, Janet Peacock ${ }^{3}$, Charles Stiller ${ }^{4}$, Claudia Wells $^{5}$, Anne Greenough ${ }^{6}$ and Irene J. Higginson ${ }^{1}$

\begin{abstract}
Background: Efforts to improve end of life care (EOLC) have made tangible impacts on care in adults, including enabling more people to die at their preferred place of death (PoD), usually home or hospices. Little is known how the PoD in children and young people (CYP, $\leq 24$ years) has changed over time, especially in the context of a series of national initiatives for EoLC improvement since the late 1990s. To inform evidence-based policy-making and service development, we evaluated the national trends of PoD and the associated factors in CYP who died with cancer.
\end{abstract}

Methods: Population-based observational study in the National Health Service (NHS) England, 1993-2014. All non-accidental CYP deaths with cancer $(N=12,774)$ were extracted from the death registration database of the Office for National Statistics (ONS).

Results: Hospital deaths reduced from $>50$ to $45 \%$, hospice deaths were rare but more than doubled from $6 \%$ in 1993-2000 to $13 \%$ in 2005-2014, and home deaths fluctuated at around $40 \%$. Those aged 0-19 years were more likely to die at home than young adults (adjusted proportion ratio (PRs): 1.23-1.62); haematological cancer patients or those with 2+ comorbid conditions had higher chances of hospital death (PRs for home: $0.18-0.75$, hospice: 0.04-0.37); deprivation was associated with a reduced chance of home death (PRs: 0.76-0.84). The residential region affected hospice but not home deaths. The variations of PoD by cause of death, comorbid conditions and deprivation slightly decreased with time.

Conclusions: Hospitals and home were the main EoLC settings for CYP with cancer. Home death rates barely changed in the past two decades; deaths in hospitals remained the most common but slightly shifted towards hospices. CYP with haematological malignancy or with comorbid conditions had persistently high hospital deaths; these cases had an even lower chance of deaths in hospices (50 \%) than at home. There were deprivation- and area-related inequalities in PoD which may need service- and/or policy-level intervention. The findings highlight a need for CYP specific initiatives to enhance EoLC support and capacities both at home and in hospices.

Keywords: End of life care, Children and young people, Place of death, Cancer, Palliative care, Inequality

Abbreviations: CYP, Children and young people; ONS, Office for National Statistics; PEoLC, Palliative and end of life care; PoD, Place of death

\footnotetext{
* Correspondence: wei.gao@kcl.ac.uk

${ }^{1}$ King's College London, Cicely Saunders Institute, Department of Palliative Care, Policy and Rehabilitation, Bessemer Road, Denmark Hill, London SE5 9PJ, UK

Full list of author information is available at the end of the article
} 


\section{Background}

A "good death" as understood by many is one that occurs at home or in a home-like environment (e.g., hospice) [1]. However, when it is weighted against the basic physical needs, which are free of pain and other symptoms, to die in one's preferred place of death (PoD) becomes far less important [2]. Children and young people (CYP) with cancer and their carers also rate the "physical comfort" as the top concern [3, 4]. Quality end of life care (EoLC) encompasses four dimensions of needs: physical, psychological, social and spiritual, and should also extend the support to family members throughout the dying process [5]. Unless these needs, particular the symptom management, can be addressed at a consistently high standard across various care settings, patients and their carers cannot meaningfully exercise their choice for PoD. In fact, most deaths are still happening in the least preferred option - hospital [6-9]. In this context, the PoD remains a useful indicator for populationbased EoLC needs and how the needs have been met.

A series of EoLC tools have been developed and sequentially implemented in the United Kingdom since late 1990s, including the Gold Standard Framework, Preferred Priorities for Care and the now phased out Liverpool Care Pathway for the Dying Patient [10-12]. The NHS End of Life Care Programme launched at the end of 2004 has contributed significantly to the roll out of these programmes $[1,13]$. Although primarily targeted for adults, these tools have also been adapted for use in CYP. From 2004, framework and strategic documents specifically designed for CYP were developed, in an attempt to raise the quality standard of EoLC $[14,15]$. At around the same time, paediatric palliative care services in England received its largest ever single investment ( $£ 48$ millions) from the Big Lottery Fund towards their nationwide development, aiming to increase the provision of, and access to, hospice and community-based support to children with cancer and other life-threatening and life-limiting conditions [16]. Recent studies in England and in the States found a PoD shift from hospitals to either home or hospices among adults who died from cancer or dementia, corresponding with the national EoLC improvement initiatives [7, 17, 18].

While to some extent overlapping with adults, CYP have their distinct care needs and characteristics [19-21]. It is essential to understand whether the primarily adultfocused national efforts worked for CYP and how. It is crucial for policy and service development. Two studies examined the population-based PoD patterns in CYP and found significant variation, but neither of them did so in the changing context $[22,23$.$] This study aimed to$ evaluate how the PoD and the determinants in CYP with cancer changed over time. We chose to focus on cancer as it is a leading non-accidental mortality in CYP [24-26], but not currently optimally served by palliative and EoLC service $[19,21]$.

\section{Methods}

\section{Study design and setting}

A population-based study in the National Health Service (NHS) England.

\section{Data sources and study populations}

Data were collected by the Office for National Statistics (ONS) from all death registrations in England, 1993-2014. By law in England, a death must be registered within 5 days, unless it becomes the subject of a coroner's inquiry. The underlying cause of death $(\mathrm{CoD})$ was recorded in the database using the $9^{\text {th }}(1993-2000)$ or $10^{\text {th }}$ (2001-2014) edition of International Classification of Diseases (ICD-9, ICD-10) codes. All non-external cause of deaths (ICD-9: E codes; ICD-10: T79-T98, Y35-36 \& Y40-Y98) that occurred before the age of 24 years, with cancer as the underlying or contributing CoD (ICD-10: C00-C97; ICD-9: 140-209), were included for this study.

\section{Variables}

The study outcome - PoD, was grouped into four categories: hospital, home, hospice, and elsewhere. Hospice, in this context, refers to a dedicated unit with in-patient beds, staffed by specialists in palliative care, and is usually freestanding from hospitals. Admission to hospice is not restricted to those at the EoL, CYP are often admitted for symptom control, or other reasons (e.g., respite care). Hospices are not for profit and do not charge for admission. Explanatory variables included: age at death $(<1,1-4,5-9,10-14,15-19,20-24)$, gender (male, female), the underlying cause of death (See Table 1 for ICD-9/10 codes) - the number of contributing cause of deaths (defined as diseases or injuries that contributed to the fatal outcome), year of death, the index of deprivation, the rural/urban indicator and the region (defined by Clinical Senate, 2013) [27] of the deceased residential address. Age was analysed as an ordered categorical variable rather than a continuous variable to facilitate interpretation and comparison with the other studies. The deprivation - an indicator of socioeconomic position [28] - was measured by the lower super output area (LSOA) quintile of the income deprivation affecting children index (IDACI), where $1=$ most deprived and $5=$ least deprived. The IDACI is calculated by the Office of the Deputy Prime Minister and measures in a local area the proportion of children under the age of 16 that live in low income households. The local areas for which the index is calculated are LSOA. A LSOA is a low-level geographic area that is designed for reporting small area statistics in England and Wales. There are 32,482 LSOAs in England; each area has a minimum population size of 1,000 and an average of 1,500 . The rural/urban settlement was classified using the 2011 Census data at the level of LSOA. We used IDACI 2001, IDACI 2004 and IDACI 2007 to map the residential area- 
Table 1 ICD-9 \& 10 codes for underlying causes of death classification

\begin{tabular}{llll}
\hline Group & Underlying cause of death* & ICD-10 codes & ICD-9 codes \\
\hline 1 & Leukaemia: ALL & C91.0 & 204.0 \\
2 & Leukaemia: AML & C92.0, C92.4, C92.5, C92.6, C92.8, C93.0, C94.0, C94.2 & 205.0, 206.0, 207.0, 207.2 \\
3 & Leukaemia: Other & C91-C95 excluding above & 204-208 excluding above \\
4 & Lymphomas: Hodgkin's & C81 & 201 \\
5 & Lymphomas: non-Hodgkin's & C82-C86 & 200,202 \\
6 & Myeloma & C90 & 203 \\
7 & Brain, other CNS \& Intracranial tumours & C70-C72, C75.1-C75.3, D32-D33, & $191-192,194.3-194.4,225,227.3-227.4$, \\
8 & Connective tissue cancer & D35.2-D35.4, D42-D43, D44.3-D44.5 237.6, 239.6 \\
9 & Bone sarcoma & C46, C47, C49 & $237.0,237.1,237.5,237$ \\
10 & Renal tumours & C40-C41 & 171 \\
11 & Hepatic tumours & C64 & 170 \\
12 & Adrenal tumors including neuroblastoma & C22 & 189.0 \\
13 & Retinoblastomas & C69.2 & 155 \\
14 & Other malignant & C00-C97 excluding all above C codes & 194.0 \\
15 & Other neoplasm & D00-D48 excluding above D codes & 190.5 \\
16 & Non-cancer & A00-B99, D50-R99 & $140-209$ excluding above \\
\hline
\end{tabular}

*Underlying causes of death grouping: Leukemia: 1-3; Lymphomas \& other haematological: 4-6; Brain \& other CNS tumors: 7; Bone \& connective tissue: 8-9; Renal/Liver/Adrenal including neuroblastoma: 10-12; Other malignant: 13-15; Non-cancer: 16

based deprivation of the deceased for the period 19932000, 2001-2004, 2005-2014, respectively. The study period was divided into three intervals in order to examine changing patterns. The division took into consideration the launch, implementation and roll-out of several national initiatives around 2004/2005 for improving EoLC $[1,13]$; and also the ONS's ICD coding system changing from the ICD-9 to the ICD-10 in 2001.

\section{Statistical analysis}

Data was first checked for errors and missing values; if the missing data was less than $5 \%$, the records were deleted using the list-wise approach [29]. Data was described using frequency, proportion and $95 \%$ confidence interval (CI). The time trend in proportion of CYP cancer deaths in four PoDs was evaluated and tested using Tobit regression models, weighted by the total number of CYP deaths and the number of CYP cancer deaths. The proportion was age- and sex-standardised using the 1993's structure. The year of death was treated as a continuous variable. The regional variation was visualised with geographical maps.

Modified Poisson regression models were used to evaluate the factors independently associated with PoD. Two sets of models were constructed separately for the three time periods: home (1) versus hospital (0), and hospice (1) versus hospital (0). All explanatory variables were kept in the model. To ensure statistical efficiency, we categorised age into three groups: $0-14,15-19,20-24$. The strength of association was measured by the proportion ratio (PR) - a measure of relative risk (RR), estimated from the periodspecific models.

Possible two-way interaction effect between factors were explored and tested, using the likelihood ratio test of nested reduced models with and without the interaction terms. The collinearity was evaluated with the condition index (CI). A CI value greater than 30 indicates the presence of collinearity. If two factors were found significantly associated with each other, sensitivity analysis would be carried out by running separate models omitting one of the concerned variables. The resulting parameter estimates would then be compared to those from the main analysis models.

All statistical tests were two-sided; statistical significance is defined as $p<0.05$. All analyses were performed using the SAS 9.4 (SAS Institute Inc, Cary, North Carolina). The GIS mapping was completed with $\mathrm{R}$ version 3.1.2 software (www.r-project.org) and R Studio Version 0.98.1091.

\section{Results}

Demographic and clinical details, information on potential confounders

Between 1993 and 2014 in England, 12,774 CYP died with cancer as an underlying or contributory cause of death, accounting for $18.7 \%$ of non-accidental causes of CYP deaths. The proportion of cancer deaths increased from 18 to $25 \%$. The number of CYP cancer deaths fell $36 \%$ from 729 in 1993 to 470 in 2014 (Fig. 1). Table 2 shows the demographic and clinical characteristics of the study population. Proportions of cancer deaths by 


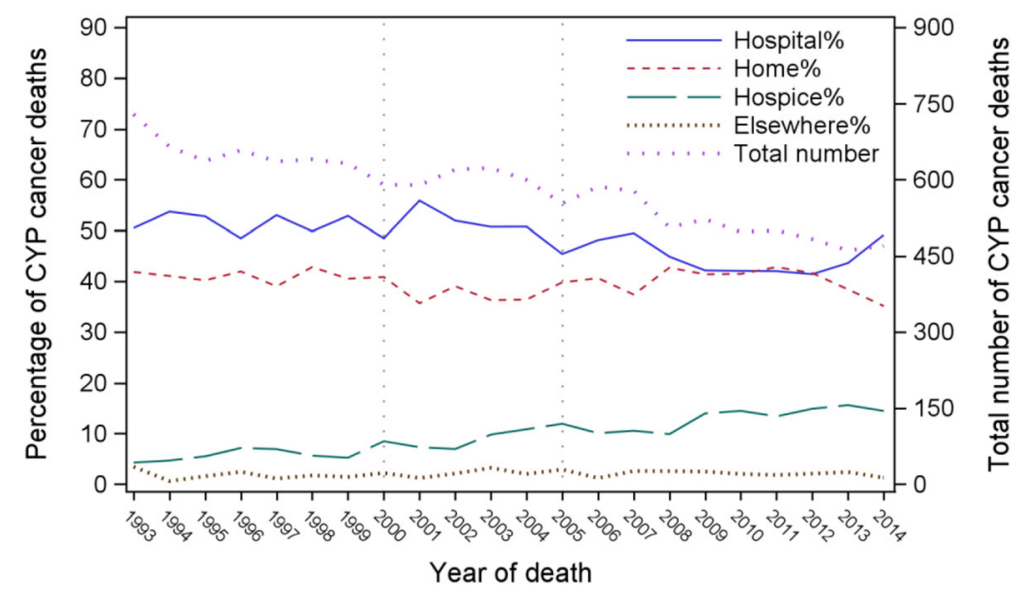

Fig. 1 Proportion of place of death and total number of deaths in children and young people who died with cancer, England 1993-2014

age group did not vary much over time, and half died aged between 15-24 years. More males than females died from cancer. Haematological malignancies (Leukaemia, Lymphoma \& other haematological cancers, $N=2580$ ) comprised over $30 \%$ of CYP cancer deaths prior to 2005, but its proportion reduced over time to the same level as brain \& CNS cancer $(27 \%, N=1369)$ in 2005-2014. A small proportion (3.2-4.2\%) of CYP with cancer died from a non-cancer cause, nearly half ( $45 \%)$ of them had a haematological cancer mentioned on their death certificates. Around $10 \%$ of CYP cancer deaths had three or more contributing causes of death. There was a small proportion increase of CYP deaths with cancer, living in the most deprived area (44 to $46 \%$ ). Most CYP dying with cancer ( $84 \%$ ) lived in an urban area (Table 2 ).

\section{Place of death and the time trends}

The proportion of hospital deaths fell from over $50 \%$ before 2005 to $45 \%$ (95 \% CI: 44-46\%) afterwards; deaths at home did not change much and fluctuated at around $40 \%$. The hospice deaths doubled from $4 \%(95 \%$ CI: $3-6 \%)$ in 1993 , to around $10 \%(n=50)$ up until 2008, followed by a further rise to $14 \%(n=73)$ in 2009 and remained constant at around that level since then (Fig. 1). Both the relative $(0.4 \%$ per year) and absolute ( 3 per year) increase of number of deaths at hospices, with the adjustment of the total number of CYP cancer deaths and CYP deaths $(p<0.001)$, were statistically significant. Most of the time hospitals were the most prevalent PoD. In 2007/ 2008 , there was a shift in place of death: hospital deaths decreased and both home and hospice deaths increased. The percentage of hospital and home deaths were similar between 2008 and 2012, after which there was a shift to more hospital and fewer home deaths, with hospital again becoming the most prevalent place for CYP with cancer spending their last moments of life (Fig. 1).

\section{Spatio-temporal variations in place of death}

The PoD varied considerably by region, but showed an overall consistent trend for a relative reduction in hospital deaths, an increase in hospice deaths and little changes in at-home deaths from the earliest to the latest periods (Fig. 2, Appendix Figures 3 and 4). In 20052014 (Fig. 2), London had the highest proportion of hospital deaths (56\%, $95 \%$ CI: 52-59 \%) and lowest home deaths (31 \%; 95 \% CI: 28-34\%); in contrast to Wessex, where hospital deaths were the lowest (33\%; $95 \%$ CI: 26-39\%) and home deaths the highest (56\%; $95 \% \mathrm{CI}$ : 49-63 \%). Hospice deaths in North East, north Cumbria, and the Hambleton \& Richmondshire districts of North Yorks and in Wessex (8 \%; $95 \%$ CI:5-12 \%) were the lowest in the country; Thames Valley, South West and South East Coast (range:14-23 \%) had the highest proportion of CYP with cancer who died in a hospice in England.

\section{Factors associated with place of death}

Multivariable modelling results for factors associated with PoD are presented in Tables 3 and 4. In all three periods, age, $\mathrm{CoD}$, number of contributing CoDs, and region were independently associated with the PoD $(P<0.001)$. Compared to young adults $(20-24)$, those aged $0-19$ years were more likely to die at home (PRs: 1.23-1.62) and less likely to die in a hospice (PRs: 0.41-0.71) than young adults, but the difference in hospice deaths was getting smaller (PRs: 0.89-0.92) and no longer significant in 2005-2014 $(P=0.42)$.

Both underlying cause of death $(\mathrm{CoD})$ and the number of contributing CoDs were strong determinants of PoD. Compared to those who died from Brain and CNS tumours, patients with a haematological cancer or noncancer as a underlying $\mathrm{CoD}$ had a significantly lower chance of dying at home (haematological cancer PRs:0.58-0.75; non-cancer PRs:0.31-0.57) or at a hospice (haematological 
Table 2 Demographical and clinical characteristics of children and young people who died with cancer, England 1993-2014 $(N=12,774)$

\begin{tabular}{|c|c|c|c|c|}
\hline \multirow[t]{2}{*}{ Variable } & \multirow[t]{2}{*}{ Value } & \multicolumn{3}{|c|}{ Year of death } \\
\hline & & 1993-2000 & $2001-2004$ & 2005-2014 \\
\hline Total & - & 5187 & 2431 & 5156 \\
\hline Average/year & - & 649 & 608 & 517 \\
\hline \multirow[t]{6}{*}{ Age } & $<1$ & 162(3.1) & $63(2.6)$ & $152(2.9)$ \\
\hline & $01-04$ & $736(14.2)$ & $325(13.4)$ & $722(14.0)$ \\
\hline & 05-09 & $887(17.1)$ & $377(15.5)$ & $785(15.2)$ \\
\hline & $10-14$ & $808(15.6)$ & $411(16.9)$ & $743(14.4)$ \\
\hline & $15-19$ & 1062(20.5) & $574(23.6)$ & $1169(22.7)$ \\
\hline & $20-24$ & 1532(29.5) & $681(28.0)$ & 1585(30.7) \\
\hline \multirow[t]{2}{*}{ Gender } & Female & 2193(42.3) & 1059(43.6) & $2244(43.5)$ \\
\hline & Male & 2994(57.7) & 1372(56.4) & $2912(56.5)$ \\
\hline \multirow{7}{*}{$\begin{array}{l}\text { Underlying } \\
\text { cause of death }\end{array}$} & Leukaemia & 1366(26.3) & $564(23.2)$ & $992(19.2)$ \\
\hline & $\begin{array}{l}\text { Lymphoma \& } \\
\text { other haem- } \\
\text { atological cancers }\end{array}$ & $447(8.6)$ & 203(8.4) & $377(7.3)$ \\
\hline & $\begin{array}{l}\text { Bone \& } \\
\text { connective }\end{array}$ & $694(13.4)$ & $384(15.8)$ & $812(15.7)$ \\
\hline & Brain \& CNS etc. & $1117(21.5)$ & $580(23.9)$ & 1384(26.8) \\
\hline & $\begin{array}{l}\text { Renal/Liver/ } \\
\text { Adrenal including } \\
\text { neuroblastoma }\end{array}$ & $467(9.0)$ & $226(9.3)$ & $498(9.7)$ \\
\hline & $\begin{array}{l}\text { Other malignant } \\
\text { \& neoplasm }\end{array}$ & $876(16.9)$ & $389(16.0)$ & $928(18.0)$ \\
\hline & Non-cancer & $220(4.2)$ & $85(3.5)$ & $165(3.2)$ \\
\hline \multirow{4}{*}{$\begin{array}{l}\text { N. contributing } \\
\text { CoDs }\end{array}$} & 0 & $2476(47.7)$ & $1209(49.7)$ & $2757(53.5)$ \\
\hline & 1 & 1703(32.8) & $680(28.0)$ & $1300(25.2)$ \\
\hline & 2 & $648(12.5)$ & $311(12.8)$ & $605(11.7)$ \\
\hline & $3+$ & $360(6.9)$ & $231(9.5)$ & 494(9.6) \\
\hline \multirow[t]{5}{*}{ IDACI quintile } & Most deprived & $1252(24.1)$ & $585(24.1)$ & $1317(25.5)$ \\
\hline & 2 & 1033(19.9) & $494(20.3)$ & 1064(20.6) \\
\hline & 3 & 1003(19.3) & $451(18.6)$ & $1002(19.4)$ \\
\hline & 4 & $909(17.5)$ & $445(18.3)$ & $879(17.0)$ \\
\hline & Least deprived & $990(19.1)$ & $456(18.8)$ & $894(17.3)$ \\
\hline \multirow[t]{2}{*}{ Settlement } & Urban & 4345(83.8) & $2031(83.5)$ & $4326(83.9)$ \\
\hline & Rural & $842(16.2)$ & $400(16.5)$ & $830(16.1)$ \\
\hline \multirow[t]{5}{*}{$\begin{array}{l}\text { Strategic } \\
\text { clinical network }\end{array}$} & $\begin{array}{l}\text { Cheshire \& } \\
\text { Merseyside }\end{array}$ & $257(5.0)$ & $118(4.9)$ & $222(4.3)$ \\
\hline & East Midlands & 463(8.9) & 209(8.6) & $467(9.1)$ \\
\hline & East of England & 512(9.9) & 283(11.6) & $578(11.2)$ \\
\hline & $\begin{array}{l}\text { Greater } \\
\text { Manchester, } \\
\text { Lancashire and } \\
\text { south Cumbria }\end{array}$ & $456(8.8)$ & 233(9.6) & $416(8.1)$ \\
\hline & London & $717(13.8)$ & $383(15.8)$ & $847(16.4)$ \\
\hline
\end{tabular}

Table 2 Demographical and clinical characteristics of children and young people who died with cancer, England 1993-2014 $(N=12,774)$ (Continued)

\begin{tabular}{|c|c|c|c|c|}
\hline & $\begin{array}{l}\text { North East, north } \\
\text { Cumbria, and the } \\
\text { Hambleton \& } \\
\text { Richmondshire } \\
\text { districts of North } \\
\text { Yorkshire }\end{array}$ & $325(6.3)$ & 136(5.6) & $281(5.4)$ \\
\hline & South East Coast & 419(8.1) & $206(8.5)$ & $424(8.2)$ \\
\hline & South West & 438(8.4) & 192(7.9) & $436(8.5)$ \\
\hline & Thames Valley & $172(3.3)$ & $85(3.5)$ & $176(3.4)$ \\
\hline & Wessex & $280(5.4)$ & $108(4.4)$ & $221(4.3)$ \\
\hline & West Midlands & $590(11.4)$ & 229(9.4) & $566(11.0)$ \\
\hline & $\begin{array}{l}\text { Yorkshire \& The } \\
\text { Humber }\end{array}$ & $558(10.8)$ & $249(10.2)$ & $522(10.1)$ \\
\hline \multirow[t]{4}{*}{ Place of death } & Hospital & $2656(51.2)$ & $1271(52.3)$ & 2317(44.9) \\
\hline & Home & 2129(41.0) & 896(36.9) & 2069(40.1) \\
\hline & Hospice & $307(5.9)$ & $212(8.7)$ & $660(12.8)$ \\
\hline & Elsewhere & $95(1.8)$ & $52(2.1)$ & $110(2.1)$ \\
\hline
\end{tabular}

cancer PRs:0.18-0.36; non-cancer PRs:0.11-0.21). The likelihood of death at home or in a hospice was inversely associated with the number of contributing CoDs. The chance of home death in CYPs with two or more contributing CoDs was less than half of that for those with no contributing CoD (PRs 0.18-0.48); the effect of contributing CoDs was more pronounced for hospice death (PRs:0.04-0.29). The inequality in $\mathrm{PoD}$ by $\mathrm{CoD}$ or by contributing CoDs showed no sign of narrowing down.

Residents of the two most deprived quintile areas had a reduced chance of death at home (PRs: 0.76-0.90); no disparities in home deaths were observed from the third to the highest quintile. The gap of the home deaths between the deprivation quintiles slightly widened during the study period. The chance of hospice death did not vary with deprivation. The geographical variation was persistent after controlling the potential confounding variables. Gender and type of settlement (rural/urban) were not related to where a CYP with cancer died.

There was significant interaction between the $\mathrm{CoD}$ and the number of CoDs in home death models $(p<0.001)$ but the condition index $(\mathrm{CI})$ did not indicate the presence of significant collinearity (intercept adjusted CIs range: 1.11-1.17). However, the PR estimations from the sensitivity analyses with one of these two factors omitted from the models were only slightly different from those from the main analysis (Appendix Tables 5, 6, 7, 8).

\section{Discussion}

This is the first population-based evaluation of the PoD and its determinants in CYP in the context of national EoLC policies and initiatives. We found that despite a 
\%deaths in hospital per $100 \mathrm{CYP}$ cancer deaths

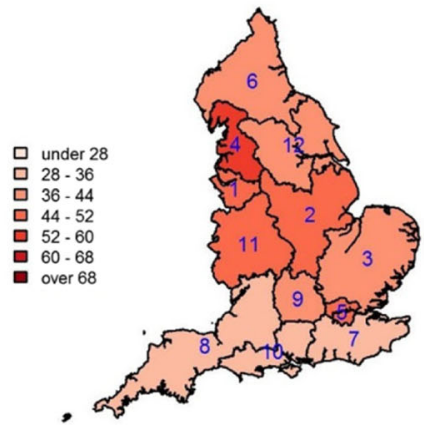

\%deaths at home per $100 \mathrm{CYP}$ cancer deaths

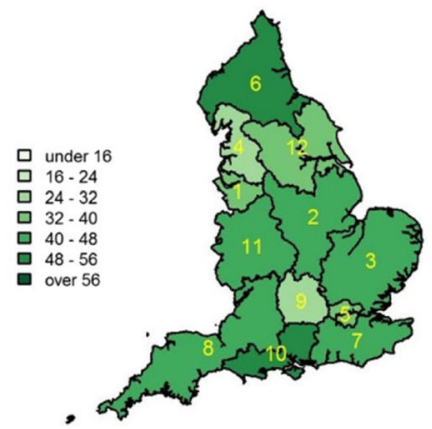

\%deaths in hospice per $100 \mathrm{CYP}$ cancer deaths

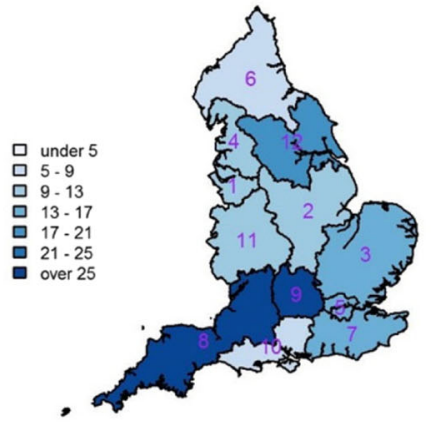

Fig. 2 Geographical variations in place of death in children and young people who died with cancer, England 2005-2014. 1: Cheshire \& Merseyside; 2: East Midlands; 3: East of England; 4: Greater Manchester, Lancashire \& south Cumbria; 5: London; 6: North East, north Cumbria and the Hambleton \&

Richmondshire districts of North Yorkshire; 7: South East Coast; 8: South West; 9: Thames Valley; 10: Wessex; 11: West Midlands; 12: Yorkshire \& the Humber

$36 \%$ reduction in CYP cancer mortality, the home death rate barely changed in the past two decades. In England, palliative care for children is typically provided at home, with support from a hospital-based oncology team coordinated by paediatric oncology outreach nurse specialists (POONS) [30]. This care model is effective in enabling home death $[17,31]$. In theory, a fallen mortality may free up some home care resources to support more home deaths. However, the benefit appeared not to be transferred. A study from Taiwan using administrative data found that the EoLC in paediatric cancer patients was aggressive with heavy use of life sustaining and curative treatments, and lack of support of deaths at home [32]. Future studies need to elucidate the roles of these factors in where children and young people die. Compared to adults, the PoD change and the reduction in inequality in CYP appeared to be of a lesser degree with a time delay (e.g., until 2008). A recent study using Medicare data demonstrated that the EoLC needs in the young population may be different from those of adults [33]. Our data suggests the inadequacy of adult focused policy interventions for CYP, highlights a need for CYPspecific national initiatives that improve PEoLC care support at home.

Hospitals remained the most common PoD for CYP with cancer, around nearly half of the deaths occurred there. There was a tendency of PoD shifting from hospitals towards hospices. The shifting coincided with the landmark launch of the national EoLC programme in Nov 2004 and subsequent national efforts [13]. The PoD in adults with cancer during the same period in England shifted towards both home and hospices with more pronounced effects on home deaths [17]. The PoD shifting outside hospitals is consistent with findings from other countries [34-36]. The hospice deaths increased but were still rather low in most England's regions, ranging from under $10 \%$ to around $20 \%$. Hospices have been mostly used as a respite service in the UK. Their potential as a great alternative to hospital in meeting the needs of managing physical symptoms has not yet been fully exploited. Future research needs to focus on how to increase and expand the use of hospice services.

Although the chance of home and hospice deaths for CYPs with most cancers improved though slowly over time, deaths of those with haematological cancer still predominantly $(\sim 70 \%)$ took place in hospitals. There was little change in this proportion over time, similar to what's seen in adults [17]. Haematological cancers accounted for nearly 1 in 3 CYP cancer deaths. Over half of the noncancer deaths had a haematological cancer as a contributing CoD. This is consistent with a previous systematic review and meta-analysis [37]. The review also highlighted that the reasons for the high hospital deaths in haematology patients are not yet clear, but likely to be multidimensional and complex. The number of CoDs has been used as a proxy measure of comorbidities [38, 39], which, in turn, translates into the care management complexity at the end of life [40]. The CYP deaths with more contributing CoDs were less likely to occur at home or in a hospice. While these results should be interpreted with caution as the recording practice may vary by location of death, constantly improving cancer survival and increasing comorbidities among cancer survivors are bound to make EoLC management more challenging $[41,42]$.

Given that home and hospices are preferred and increasingly important for CYP cancer patients to spend their last moments of life, the healthcare system should be better equipped to meet such needs. Surprisingly, compared to those with no contributing CoDs, a patient with two or more contributing CoDs had $80 \%$ lower chance of dying in a hospice, even lower than that of home deaths. It appears that when it comes to cases with comorbid conditions, hospice as a dedicated EoLC facility does not seem to be more advantageous than 
Table 3 Factors associated * with home deaths (versus hospital deaths) in children and young people with cancer, England 1993-2014 $(N=12,774)$

\begin{tabular}{|c|c|c|c|c|}
\hline \multirow[t]{2}{*}{ Variable } & \multirow[t]{2}{*}{ Value } & \multicolumn{3}{|l|}{ Year of death } \\
\hline & & $1993-2000$ & $2001-2004$ & $2005-2014$ \\
\hline \multirow[t]{2}{*}{ Age(ref: 20-24) } & $0-14$ & $1.62(1.44$ to 1.82$)$ & $1.51(1.26$ to 1.82$)$ & $1.34(1.19$ to 1.50$)$ \\
\hline & $15-19$ & $1.23(1.07$ to 1.41$)$ & $1.39(1.14$ to 1.71$)$ & $1.28(1.12$ to 1.45$)$ \\
\hline Gender & Male vs female & $1.07(0.98$ to 1.16$)$ & $1.04(0.91$ to 1.19$)$ & $1.06(0.97$ to 1.15$)$ \\
\hline \multirow{6}{*}{$\begin{array}{l}\text { Underlying cause of death } \\
\text { (ref: Brain \& CNS) }\end{array}$} & Leukaemia & $0.72(0.63$ to 0.82$)$ & $0.73(0.60$ to 0.90$)$ & $0.58(0.51$ to 0.68$)$ \\
\hline & Lymphoma \& other haematology & $0.75(0.61$ to 0.91$)$ & $0.65(0.47$ to 0.88$)$ & $0.60(0.48$ to 0.74$)$ \\
\hline & Bone \& connective & $1.39(1.21$ to 1.59$)$ & $1.29(1.06$ to 1.57$)$ & $1.07(0.95$ to 1.21$)$ \\
\hline & Renal/Liver/Adrenal including neuroblastoma & $1.20(1.04$ to 1.39$)$ & $1.27(1.02$ to 1.57$)$ & $0.93(0.80$ to 1.07$)$ \\
\hline & Other malignant & $1.08(0.94$ to 1.24$)$ & $0.90(0.71$ to 1.14$)$ & $0.90(0.78$ to 1.03$)$ \\
\hline & Non-cancer & $0.31(0.19$ to 0.49$)$ & $0.33(0.15$ to 0.75$)$ & $0.57(0.37$ to 0.87$)$ \\
\hline \multirow[t]{3}{*}{ N. contributing CoDs (ref: 0 ) } & 1 & $0.82(0.75$ to 0.91$)$ & $0.81(0.70$ to 0.94$)$ & $0.82(0.74$ to 0.91$)$ \\
\hline & 2 & $0.48(0.40$ to 0.57$)$ & $0.33(0.24$ to 0.45$)$ & $0.40(0.33$ to 0.48$)$ \\
\hline & $3+$ & $0.26(0.19$ to 0.36$)$ & $0.18(0.11$ to 0.29$)$ & $0.18(0.13$ to 0.25$)$ \\
\hline \multirow[t]{4}{*}{ Deprivation (ref: 5 least deprived) } & 1 (most deprived) & $0.85(0.74$ to 0.97$)$ & $0.77(0.61$ to 0.96$)$ & $0.76(0.66$ to 0.88$)$ \\
\hline & 2 & $0.90(0.78$ to 1.03$)$ & $0.97(0.78$ to 1.20$)$ & $0.83(0.72$ to 0.96$)$ \\
\hline & 3 & $0.95(0.84$ to 1.09$)$ & $1.02(0.82$ to 1.25$)$ & $1.00(0.87$ to 1.14$)$ \\
\hline & 4 & $0.97(0.84$ to 1.11$)$ & 1.09 (0.89 to 1.34$)$ & $0.99(0.86$ to 1.13$)$ \\
\hline Rural/urban indicator & Rural vs Urban & $1.07(0.95$ to 1.20$)$ & $1.08(0.90$ to 1.29$)$ & $1.00(0.89$ to 1.13$)$ \\
\hline \multirow[t]{11}{*}{ SCN region (ref: London) } & Cheshire \& Merseyside & $1.17(0.93$ to 1.48$)$ & $1.19(0.84$ to 1.67$)$ & $1.01(0.78$ to 1.30$)$ \\
\hline & East Midlands & $1.03(0.84$ to 1.25$)$ & $1.03(0.77$ to 1.38$)$ & $1.09(0.90$ to 1.32$)$ \\
\hline & East of England & $1.27(1.06$ to 1.52$)$ & $1.07(0.82$ to 1.41$)$ & $1.26(1.06$ to 1.51$)$ \\
\hline & Greater Manchester, Lancashire and south Cumbria & $1.10(0.90$ to 1.34$)$ & $0.94(0.69$ to 1.27$)$ & $1.07(0.87$ to 1.32$)$ \\
\hline & $\begin{array}{l}\text { North East, north Cumbria, and the Hambleton \& } \\
\text { Richmondshire districts of North Yorkshire }\end{array}$ & $1.23(1.01$ to 1.52$)$ & $1.42(1.05$ to 1.93$)$ & $1.41(1.14$ to 1.73$)$ \\
\hline & South East Coast & $1.06(0.87$ to 1.30$)$ & $1.21(0.91$ to 1.61$)$ & $1.26(1.04$ to 1.53$)$ \\
\hline & South West & $1.24(1.02$ to 1.50$)$ & $1.03(0.76$ to 1.41$)$ & $1.28(1.06$ to 1.56$)$ \\
\hline & Thames Valley & $1.21(0.93$ to 1.57$)$ & $1.14(0.77$ to 1.68$)$ & $1.09(0.82$ to 1.45$)$ \\
\hline & Wessex & $1.25(1.01$ to 1.54$)$ & $1.17(0.84$ to 1.64$)$ & $1.43(1.15$ to 1.78$)$ \\
\hline & West Midlands & $1.18(0.99$ to 1.41$)$ & $0.86(0.63$ to 1.17$)$ & $1.23(1.03$ to 1.48$)$ \\
\hline & Yorkshire \& The Humber & $0.94(0.78$ to 1.14$)$ & $1.08(0.82$ to 1.44$)$ & $1.12(0.93$ to 1.35$)$ \\
\hline
\end{tabular}

*The association is measured by proportion ratios(PRs) and $95 \%$ confidence intervals. PR $>1$ indicates a higher probability of home deaths, $<1$ lower chance of home deaths, $\mathrm{PR}=1$ indicates no association. The PRs were derived from modified Poisson regression model, adjusting for the listed variables, the number of CYP deaths and the number of CYP cancer deaths at SCN region level

people's own home. Further investigations to the reasons are needed. The level of deprivation was related to lower chances of home deaths but not hospice deaths, the inequality gap showed little sign of closing up. The wide regional variations in $\mathrm{PoD}$ are worth exploring in depth, as a better understanding of these variations may reveal important clues for local practices, policies and service configurations that facilitate and enable home or hospice death.

It is worth noting that these findings were observed in the background of a relative increase (from 18 to $25 \%$ ) in CYP cancer deaths, partly due to the mortality reduction in competing causes of death (e.g., diabetes, asthma) [43]. This trend is likely to continue, given the rise of the cancer incidence [44]. Our findings suggest that even in the traditionally and relatively better served disease group - cancer [45], the end of life care for CYP is suboptimal. It is even more unfortunate, as it happened in a country ranked consistently the best in the world for its quality of death [46]. There is a pressing need for national and international actions to improve end of life care for this neglected CYP population.

This study has several limitations. We did not have information regarding care and transition of the care 
Table 4 Factors associated * with hospice deaths (versus hospital deaths) in children and young people with cancer, England $1993-2014(N=12,774)$

\begin{tabular}{|c|c|c|c|c|}
\hline \multirow[t]{2}{*}{ Variable } & \multirow[t]{2}{*}{ Value } & \multicolumn{3}{|l|}{ Year of death } \\
\hline & & 1993-2000 & $2001-2004$ & $2005-2014$ \\
\hline \multirow[t]{2}{*}{ Age(ref: 20-24) } & $0-14$ & $0.41(0.31$ to 0.54$)$ & $0.71(0.51$ to 0.98$)$ & $0.91(0.76$ to 1.10$)$ \\
\hline & $15-19$ & $0.56(0.40$ to 0.76$)$ & $0.63(0.42$ to 0.93$)$ & $0.92(0.74$ to 1.14$)$ \\
\hline Gender & Male vs female & $0.86(0.68$ to 1.07$)$ & $0.86(0.65$ to 1.13$)$ & $0.92(0.79$ to 1.08$)$ \\
\hline \multirow{6}{*}{$\begin{array}{l}\text { Underlying cause of death } \\
\text { (ref: Brain \& CNS) }\end{array}$} & Leukaemia & $0.26(0.18$ to 0.39$)$ & $0.35(0.22$ to 0.57$)$ & $0.26(0.19$ to 0.35$)$ \\
\hline & Lymphoma \& other haematology & $0.29(0.17$ to 0.48$)$ & $0.18(0.08$ to 0.43$)$ & $0.36(0.24$ to 0.53$)$ \\
\hline & Bone \& connective & $0.93(0.65$ to 1.32$)$ & $0.98(0.66$ to 1.44$)$ & $0.79(0.63$ to 1.00$)$ \\
\hline & Renal/Liver/Adrenal including neuroblastoma & $0.76(0.46$ to 1.24$)$ & $0.86(0.49$ to 1.48$)$ & $0.53(0.39$ to 0.73$)$ \\
\hline & Other malignant & $0.77(0.57$ to 1.05$)$ & $0.79(0.53$ to 1.17$)$ & $0.82(0.67$ to 1.02$)$ \\
\hline & Non-cancer & $0.21(0.06$ to 0.67$)$ & $0.14(0.02$ to 1.03$)$ & $0.11(0.03$ to 0.46$)$ \\
\hline \multirow[t]{3}{*}{ N. contributing CoDs (ref: 0) } & 1 & $0.81(0.64$ to 1.03$)$ & $0.53(0.37$ to 0.75$)$ & $0.62(0.51$ to 0.75$)$ \\
\hline & 2 & $0.29(0.17$ to 0.49$)$ & $0.25(0.13$ to 0.46$)$ & $0.22(0.15$ to 0.32$)$ \\
\hline & $3+$ & $0.04(0.01$ to 0.26$)$ & $0.15(0.06$ to 0.36$)$ & $0.16(0.10$ to 0.26$)$ \\
\hline \multirow[t]{4}{*}{ Deprivation (ref: 5 least deprived) } & 1 (most deprived) & $0.99(0.71$ to 1.39$)$ & $0.82(0.52$ to 1.29$)$ & $0.91(0.71$ to 1.18$)$ \\
\hline & 2 & $0.92(0.64$ to 1.31$)$ & $1.06(0.68$ to 1.64$)$ & $0.84(0.65$ to 1.09$)$ \\
\hline & 3 & $0.72(0.49$ to 1.05$)$ & $1.15(0.74$ to 1.78$)$ & $1.00(0.78$ to 1.29$)$ \\
\hline & 4 & $0.76(0.52$ to 1.12$)$ & $0.97(0.61$ to 1.55$)$ & $0.92(0.70$ to 1.20$)$ \\
\hline Rural/Urban indicator & Rural vs Urban & $0.99(0.70$ to 1.40$)$ & $1.08(0.73$ to 1.60$)$ & $0.96(0.77$ to 1.21$)$ \\
\hline \multirow[t]{11}{*}{ SCN region (ref: London) } & Cheshire \& Merseyside & $2.06(1.10$ to 3.85$)$ & $1.18(0.55$ to 2.52$)$ & $0.91(0.59$ to 1.41$)$ \\
\hline & East Midlands & $0.98(0.51$ to 1.90$)$ & $0.69(0.33$ to 1.42$)$ & $0.97(0.69$ to 1.38$)$ \\
\hline & East of England & $1.51(0.84$ to 2.73$)$ & $1.57(0.91$ to 2.69$)$ & $1.24(0.91$ to 1.70$)$ \\
\hline & Greater Manchester, Lancashire and south Cumbria & $3.43(2.12$ to 5.58$)$ & $1.55(0.92$ to 2.63$)$ & $1.06(0.76$ to 1.48$)$ \\
\hline & $\begin{array}{l}\text { North East, north Cumbria, and the Hambleton } \\
\& \text { Richmondshire districts of North Yorkshire }\end{array}$ & $1.04(0.48$ to 2.26$)$ & $0.66(0.23$ to 1.90$)$ & $0.96(0.60$ to 1.54$)$ \\
\hline & South East Coast & $2.46(1.42$ to 4.27$)$ & $1.62(0.89$ to 2.97$)$ & $1.38(0.99$ to 1.92$)$ \\
\hline & South West & $2.27(1.30$ to 3.97$)$ & $1.38(0.75$ to 2.53$)$ & $1.83(1.35$ to 2.47$)$ \\
\hline & Thames Valley & $1.74(0.77$ to 3.93$)$ & $0.85(0.34$ to 2.10$)$ & $1.71(1.18$ to 2.48$)$ \\
\hline & Wessex & $1.22(0.58$ to 2.59$)$ & $0.52(0.18$ to 1.53$)$ & $0.99(0.59$ to 1.68$)$ \\
\hline & West Midlands & $2.05(1.22$ to 3.42$)$ & $0.88(0.48$ to 1.61$)$ & $1.13(0.82$ to 1.54$)$ \\
\hline & Yorkshire \& The Humber & $2.44(1.49$ to 4.02$)$ & $1.75(1.03$ to 2.98$)$ & $1.14(0.83$ to 1.56$)$ \\
\hline
\end{tabular}

*The association is measured by proportion ratios(PRs) and $95 \%$ confidence intervals. PR $>1$ indicates a higher probability of hospice deaths, $<1$ lower chance of hospice deaths, $\mathrm{PR}=1$ indicates no association. The PRs were derived from modified Poisson regression model, adjusting for the listed variables, the number of CYP deaths and the number of CYP cancer deaths at SCN region level

settings; the death certificate data only contains an individual's final PoD. Even if a patient was admitted to a hospital in the last minute and died there, the PoD will be recorded as the hospital. There is evidence that preferred PoD may differ from preferred place of $\operatorname{care}^{25}$. We should also note that we did not have information on preferences of the patient and family members, or indicators for clinical appropriateness of PoD. Nevertheless, as a patient and/or their carer's preference for where to die is highly dependent on the level of care support one can get in a specific setting $[2,47]$, the PoD is still a useful indicator for EoLC needs and to what extent the need has been met.

\section{Conclusions}

Hospitals and home were the main EoLC setting for CYP with cancer. The home death rate $(\sim 40 \%)$ barely changed in the past two decades, and deaths in hospital remained the most common but slightly shifted towards hospices. CYP with haematological malignancy and with comorbid conditions had persistently high hospital deaths; the chance of these cases with deaths in hospices was even lower than at home. There were deprivation- and arearelated inequalities in PoD which may need service-level change and/or policy-level intervention. The findings highlight a need for CYP specific initiatives to enhance EoLC support and capacities at home and in hospices. 


\section{Appendix}
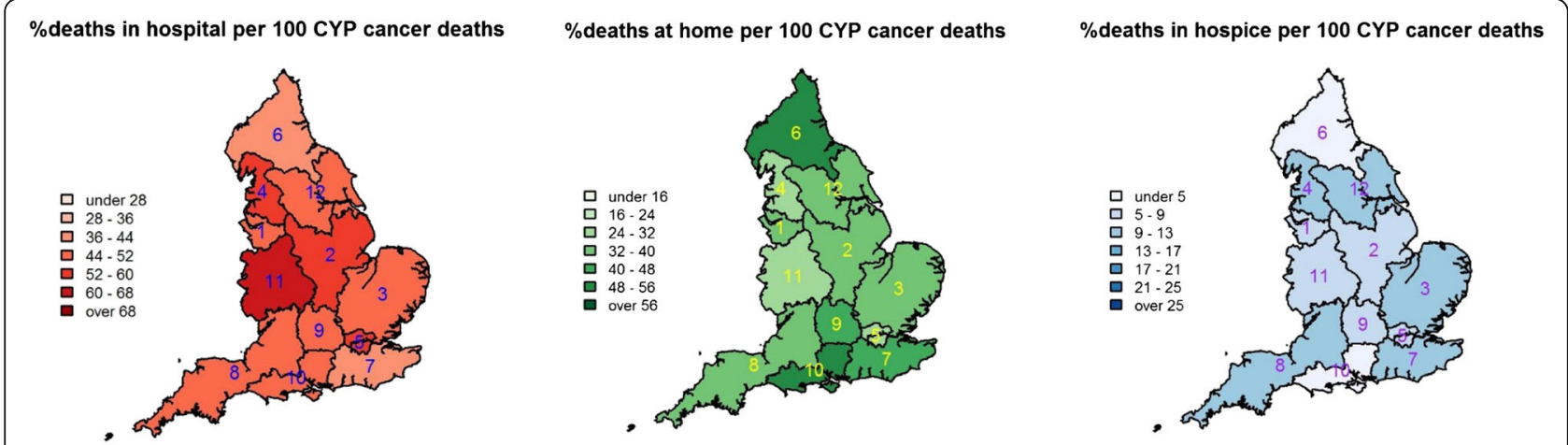

Fig. 3 Geographical variations in place of death in children and young people who died with cancer, England 2001-2004. 1: Cheshire \& Merseyside; 2: East Midlands; 3: East of England; 4: Greater Manchester, Lancashire \& South Cumbria; 5: London; 6: North East, North Cumbria and the Hambleton \& Richmondshire districts of North Yorkshire; 7: South East Coast; 8: South West; 9: Thames Valley; 10: Wessex; 11: West Midlands; 12: Yorkshire \& the Humber

\%deaths in hospital per 100 CYP cancer deaths

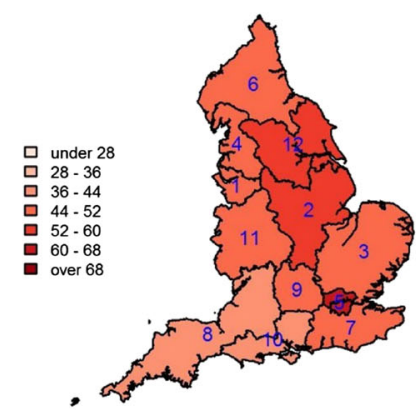

\%deaths at home per 100 CYP cancer deaths

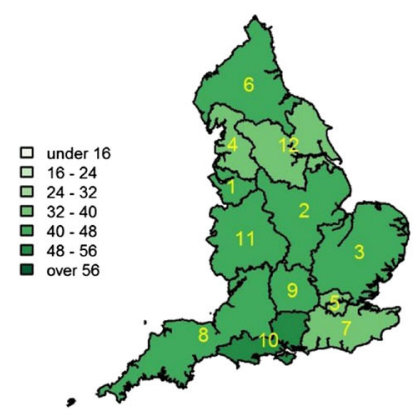

\%deaths in hospice per 100 CYP cancer deaths

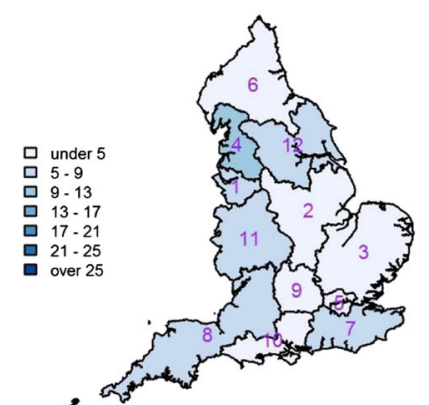

Fig. 4 Geographical variations in place of death in children and young people who died with cancer, England 1993-2000. 1: Cheshire \& Merseyside; 2: East Midlands; 3: East of England; 4: Greater Manchester, Lancashire \& South Cumbria; 5: London; 6: North East, North Cumbria and the Hambleton \& Richmondshire districts of North Yorkshire; 7: South East Coast; 8: South West; 9: Thames Valley; 10: Wessex; 11: West Midlands; 12: Yorkshire \& the Humber 
Table 5 Factors associated * with home death(versus hospital death) in children and young people with cancer, England $1993-2014(N=12,774)$

\begin{tabular}{|c|c|c|c|c|}
\hline \multirow[t]{2}{*}{ Variable } & \multirow[t]{2}{*}{ Value } & \multicolumn{3}{|l|}{ Year of death } \\
\hline & & $1993-2000$ & $2001-2004$ & $2005-2014$ \\
\hline \multirow[t]{2}{*}{ Age(ref: 20-24) } & $0-14$ & $1.64(1.46$ to 1.84$)$ & $1.47(1.23$ to 1.77$)$ & $1.34(1.19$ to 1.50$)$ \\
\hline & $15-19$ & $1.23(1.07$ to 1.42$)$ & $1.33(1.09$ to 1.63$)$ & $1.24(1.10$ to 1.41$)$ \\
\hline Gender & Male vs female & $1.07(0.98$ to 1.17$)$ & $1.06(0.93$ to 1.21$)$ & $1.06(0.98$ to 1.16$)$ \\
\hline \multirow{6}{*}{$\begin{array}{l}\text { Underlying cause of death } \\
\text { (ref: Brain \& CNS) }\end{array}$} & Leukaemia & $0.65(0.57$ to 0.74$)$ & $0.60(0.49$ to 0.74$)$ & $0.47(0.41$ to 0.55$)$ \\
\hline & Lymphoma \& other haematology & $0.71(0.58$ to 0.86$)$ & $0.59(0.44$ to 0.81$)$ & $0.52(0.42$ to 0.65$)$ \\
\hline & Bone \& connective & $1.33(1.16$ to 1.52$)$ & $1.27(1.04$ to 1.54$)$ & $1.08(0.96$ to 1.23$)$ \\
\hline & Renal/Liver/Adrenal including neuroblastoma & $1.18(1.02$ to 1.36$)$ & $1.31(1.06$ to 1.62$)$ & $0.92(0.79$ to 1.06$)$ \\
\hline & Other malignant & $1.02(0.89$ to 1.17$)$ & $0.79(0.63$ to 1.00$)$ & $0.83(0.72$ to 0.95$)$ \\
\hline & Non-cancer & $0.18(0.11$ to 0.28$)$ & $0.15(0.07$ to 0.34$)$ & $0.26(0.18$ to 0.40$)$ \\
\hline \multirow[t]{4}{*}{ Deprivation (ref: 5 least deprived) } & 1 (most deprived) & $0.83(0.73$ to 0.96$)$ & $0.78(0.62$ to 0.97$)$ & $0.72(0.63$ to 0.84$)$ \\
\hline & 2 & $0.88(0.76$ to 1.01$)$ & $0.98(0.79$ to 1.21$)$ & $0.81(0.70$ to 0.93$)$ \\
\hline & 3 & $0.94(0.83$ to 1.08$)$ & $1.02(0.82$ to 1.25$)$ & $0.98(0.85$ to 1.12$)$ \\
\hline & 4 & $0.95(0.83$ to 1.08$)$ & $1.12(0.91$ to 1.37$)$ & $0.99(0.87$ to 1.14$)$ \\
\hline Rural/urban indicator & Rural vs Urban & $1.07(0.95$ to 1.20$)$ & $1.08(0.90$ to 1.28$)$ & $1.03(0.91$ to 1.15$)$ \\
\hline \multirow[t]{11}{*}{ SCN region (ref: London) } & Cheshire \& Merseyside & $1.19(0.95$ to 1.50$)$ & $1.27(0.90$ to 1.79$)$ & $1.04(0.81$ to 1.34$)$ \\
\hline & East Midlands & $1.07(0.88$ to 1.30$)$ & $1.10(0.82$ to 1.47$)$ & $1.12(0.92$ to 1.35$)$ \\
\hline & East of England & $1.30(1.08$ to 1.56$)$ & $1.08(0.82$ to 1.42$)$ & $1.26(1.05$ to 1.50$)$ \\
\hline & Greater Manchester, Lancashire and south Cumbria & $1.15(0.95$ to 1.41$)$ & $0.96(0.71$ to 1.30$)$ & $1.07(0.87$ to 1.31$)$ \\
\hline & $\begin{array}{l}\text { North East, north Cumbria, and the Hambleton \& } \\
\text { Richmondshire districts of North Yorkshire }\end{array}$ & $1.29(1.05$ to 1.59$)$ & $1.41(1.04$ to 1.91$)$ & $1.48(1.20$ to 1.83$)$ \\
\hline & South East Coast & $1.11(0.91$ to 1.36$)$ & $1.22(0.92$ to 1.62$)$ & $1.27(1.05$ to 1.54$)$ \\
\hline & South West & $1.30(1.07$ to 1.57$)$ & $1.04(0.77$ to 1.42$)$ & $1.30(1.07$ to 1.58$)$ \\
\hline & Thames Valley & $1.28(0.99$ to 1.66$)$ & $1.15(0.78$ to 1.69$)$ & $1.11(0.84$ to 1.48$)$ \\
\hline & Wessex & $1.35(1.09$ to 1.67$)$ & $1.19(0.85$ to 1.66$)$ & $1.48(1.19$ to 1.84$)$ \\
\hline & West Midlands & $1.21(1.01$ to 1.44$)$ & $0.84(0.61$ to 1.14$)$ & $1.22(1.02$ to 1.46$)$ \\
\hline & Yorkshire \& The Humber & $0.94(0.78$ to 1.15$)$ & $1.07(0.81$ to 1.42$)$ & $1.17(0.97$ to 1.41$)$ \\
\hline
\end{tabular}

*The association is measured by proportion ratios(PRs) and $95 \%$ confidence intervals. PR $>1$ indicates a higher probability of home death, $<1$ lower chance of home death, $\mathrm{PR}=1$ indicates no association. The PRs were derived from modified Poisson regression model, adjusting for the listed variables in the main analysis but with the omission of the number of contributing CoDs, the number of CYP deaths and the number of CYP cancer deaths at SCN region level 
Table 6 Factors associated * with home death(versus hospital death) in children and young people with cancer, England $1993-2014(N=12,774)$

\begin{tabular}{|c|c|c|c|c|}
\hline \multirow[t]{2}{*}{ Variable } & \multirow[t]{2}{*}{ Value } & \multicolumn{3}{|l|}{ Year of death } \\
\hline & & 1993-2000 & $2001-2004$ & $2005-2014$ \\
\hline \multirow[t]{2}{*}{ Age(ref: 20-24) } & $0-14$ & $1.62(1.45$ to 1.80$)$ & $1.58(1.33$ to 1.88$)$ & $1.37(1.23$ to 1.53$)$ \\
\hline & $15-19$ & $1.22(1.06$ to 1.40$)$ & $1.45(1.19$ to 1.78$)$ & $1.30(1.15$ to 1.48$)$ \\
\hline Gender & Male vs female & $1.05(0.97$ to 1.15$)$ & $1.01(0.89$ to 1.16$)$ & $1.04(0.96$ to 1.14$)$ \\
\hline \multirow[t]{3}{*}{ N. contributing CoDs (ref: 0 ) } & 1 & $0.85(0.77$ to 0.93$)$ & $0.80(0.69$ to 0.93$)$ & $0.81(0.73$ to 0.89$)$ \\
\hline & 2 & $0.42(0.35$ to 0.50$)$ & $0.28(0.21$ to 0.38$)$ & $0.35(0.29$ to 0.42$)$ \\
\hline & $3+$ & $0.20(0.15$ to 0.28$)$ & $0.15(0.09$ to 0.24$)$ & $0.15(0.11$ to 0.20$)$ \\
\hline \multirow[t]{4}{*}{ Deprivation (ref: 5 least deprived) } & 1 (most deprived) & $0.85(0.74$ to 0.97$)$ & $0.77(0.62$ to 0.97$)$ & $0.75(0.65$ to 0.87$)$ \\
\hline & 2 & $0.89(0.78$ to 1.02$)$ & $0.99(0.80$ to 1.22$)$ & $0.82(0.71$ to 0.95$)$ \\
\hline & 3 & $0.94(0.82$ to 1.07$)$ & $1.05(0.85$ to 1.30$)$ & $0.98(0.86$ to 1.12$)$ \\
\hline & 4 & $0.96(0.84$ to 1.10$)$ & 1.09 (0.89 to 1.33$)$ & $0.99(0.86$ to 1.13$)$ \\
\hline Rural/Urban indicator & Rural vs Urban & $1.07(0.95$ to 1.20$)$ & $1.10(0.92$ to 1.31$)$ & $1.01(0.89$ to 1.13$)$ \\
\hline \multirow[t]{11}{*}{ SCN region (ref: London) } & Cheshire \& Merseyside & $1.18(0.94$ to 1.49$)$ & $1.14(0.81$ to 1.60$)$ & $1.01(0.78$ to 1.29$)$ \\
\hline & East Midlands & $1.06(0.87$ to 1.28$)$ & $1.03(0.77$ to 1.38$)$ & $1.08(0.90$ to 1.31$)$ \\
\hline & East of England & $1.29(1.08$ to 1.55$)$ & $1.14(0.87$ to 1.50$)$ & $1.26(1.05$ to 1.51$)$ \\
\hline & Greater Manchester, Lancashire and south Cumbria & $1.12(0.91$ to 1.36$)$ & $0.97(0.72$ to 1.31$)$ & $1.05(0.86$ to 1.29$)$ \\
\hline & $\begin{array}{l}\text { North East, north Cumbria, and the Hambleton } \\
\& \text { Richmondshire districts of North Yorkshire }\end{array}$ & $1.23(1.00$ to 1.51$)$ & $1.51(1.11$ to 2.04$)$ & $1.41(1.14$ to 1.73$)$ \\
\hline & South East Coast & $1.07(0.88$ to 1.32$)$ & $1.27(0.96$ to 1.69$)$ & $1.27(1.05$ to 1.55$)$ \\
\hline & South West & $1.27(1.05$ to 1.54$)$ & $1.05(0.77$ to 1.43$)$ & $1.29(1.06$ to 1.57$)$ \\
\hline & Thames Valley & $1.20(0.93$ to 1.56$)$ & $1.17(0.79$ to 1.72$)$ & $1.08(0.82$ to 1.44$)$ \\
\hline & Wessex & $1.28(1.03$ to 1.58$)$ & $1.27(0.91$ to 1.77$)$ & $1.45(1.16$ to 1.80$)$ \\
\hline & West Midlands & $1.20(1.00$ to 1.43$)$ & $0.89(0.65$ to 1.20$)$ & $1.22(1.02$ to 1.46$)$ \\
\hline & Yorkshire \& The Humber & $0.96(0.79$ to 1.17$)$ & $1.12(0.84$ to 1.48$)$ & $1.12(0.93$ to 1.35$)$ \\
\hline
\end{tabular}

*The association is measured by proportion ratios(PRs) and $95 \%$ confidence intervals. PR $>1$ indicates a higher probability of hospice death, $<1$ lower chance of hospice death, $\mathrm{PR}=1$ indicates no association. The PRs were derived from modified Poisson regression model, adjusting for the listed variables in the main analysis but with the omission of the Underlying CoD, number of CYP deaths and number of CYP cancer deaths at SCN region level. -: not estimable 
Table 7 Factors associated * with hospice death(versus hospital death) in children and young people with cancer, England 1993-2014( $N=12,774)$

\begin{tabular}{|c|c|c|c|c|}
\hline \multirow[t]{2}{*}{ Variable } & \multirow[t]{2}{*}{ Value } & \multicolumn{3}{|l|}{ Year of death } \\
\hline & & 1993-2000 & $2001-2004$ & $2005-2014$ \\
\hline \multirow[t]{2}{*}{ Age (ref: 20-24) } & $0-14$ & $0.37(0.28$ to 0.49$)$ & $0.59(0.43$ to 0.81$)$ & $0.85(0.71$ to 1.02$)$ \\
\hline & $15-19$ & $0.54(0.39$ to 0.74$)$ & $0.54(0.37$ to 0.80$)$ & $0.82(0.66$ to 1.02$)$ \\
\hline Gender & Male vs female & $0.85(0.68$ to 1.07$)$ & $0.89(0.68$ to 1.16$)$ & $0.94(0.80$ to 1.09$)$ \\
\hline \multirow{6}{*}{$\begin{array}{l}\text { Underlying cause of death } \\
\text { (ref: Brain \& CNS) }\end{array}$} & Leukaemia & $0.21(0.14$ to 0.31$)$ & $0.25(0.16$ to 0.40$)$ & $0.17(0.13$ to 0.24$)$ \\
\hline & Lymphoma \& other haematology & $0.26(0.16$ to 0.43$)$ & $0.16(0.07$ to 0.36$)$ & $0.29(0.20$ to 0.43$)$ \\
\hline & Bone \& connective & $0.86(0.61$ to 1.21$)$ & $0.96(0.65$ to 1.41$)$ & $0.80(0.64$ to 1.01$)$ \\
\hline & Renal/Liver/Adrenal including neuroblastoma & $0.71(0.43$ to 1.16$)$ & $0.85(0.49$ to 1.48$)$ & $0.51(0.37$ to 0.70$)$ \\
\hline & Other malignant & $0.72(0.53$ to 0.97$)$ & $0.68(0.46$ to 1.00$)$ & $0.73(0.59$ to 0.90$)$ \\
\hline & Non-cancer & $0.09(0.03$ to 0.28$)$ & $0.05(0.01$ to 0.39$)$ & $0.04(0.01$ to 0.16$)$ \\
\hline \multirow[t]{4}{*}{ Deprivation (ref: 5 least deprived) } & 1 (most deprived) & $0.99(0.71$ to 1.39$)$ & $0.94(0.60$ to 1.48$)$ & $0.88(0.68$ to 1.13$)$ \\
\hline & 2 & $0.89(0.62$ to 1.28$)$ & $1.15(0.74$ to 1.77$)$ & $0.82(0.64$ to 1.07$)$ \\
\hline & 3 & $0.70(0.48$ to 1.02$)$ & $1.18(0.76$ to 1.84$)$ & $0.97(0.75$ to 1.25$)$ \\
\hline & 4 & $0.73(0.50$ to 1.07$)$ & $1.03(0.65$ to 1.64$)$ & $0.92(0.70$ to 1.20$)$ \\
\hline Rural/urban indicator & Rural vs Urban & $0.99(0.70$ to 1.39$)$ & $1.11(0.75$ to 1.64$)$ & $0.99(0.78$ to 1.24$)$ \\
\hline \multirow[t]{11}{*}{ SCN region (ref: London) } & Cheshire \& Merseyside & $2.09(1.12$ to 3.91$)$ & $1.27(0.59$ to 2.72$)$ & $0.99(0.64$ to 1.53$)$ \\
\hline & East Midlands & $1.01(0.52$ to 1.95$)$ & $0.78(0.38$ to 1.61$)$ & $1.00(0.71$ to 1.42$)$ \\
\hline & East of England & $1.58(0.88$ to 2.86$)$ & $1.66(0.97$ to 2.86$)$ & $1.22(0.89$ to 1.67$)$ \\
\hline & Greater Manchester, Lancashire and south Cumbria & $3.57(2.20$ to 5.81$)$ & $1.64(0.97$ to 2.78$)$ & $1.08(0.78$ to 1.52$)$ \\
\hline & $\begin{array}{l}\text { North East, north Cumbria, and the Hambleton \& } \\
\text { Richmondshire districts of North Yorkshire }\end{array}$ & $1.07(0.49$ to 2.31$)$ & $0.59(0.21$ to 1.71$)$ & $1.03(0.64$ to 1.65$)$ \\
\hline & South East Coast & $2.60(1.50$ to 4.50$)$ & $1.57(0.86$ to 2.86$)$ & $1.39(1.00$ to 1.94$)$ \\
\hline & South West & $2.34(1.34$ to 4.10$)$ & $1.40(0.76$ to 2.59$)$ & $1.81(1.34$ to 2.45$)$ \\
\hline & Thames Valley & $1.84(0.82$ to 4.15$)$ & $0.99(0.40$ to 2.45$)$ & $1.81(1.25$ to 2.62$)$ \\
\hline & Wessex & $1.36(0.64$ to 2.88$)$ & $0.52(0.18$ to 1.51$)$ & $0.99(0.58$ to 1.67$)$ \\
\hline & West Midlands & $2.09(1.25$ to 3.49$)$ & $0.87(0.47$ to 1.59$)$ & $1.12(0.82$ to 1.54$)$ \\
\hline & Yorkshire \& The Humber & $2.40(1.46$ to 3.94$)$ & $1.83(1.08$ to 3.11$)$ & $1.24(0.91$ to 1.69$)$ \\
\hline
\end{tabular}

*The association is measured by proportion ratios(PRs) and $95 \%$ confidence intervals. PR $>1$ indicates a higher probability of home death, $<1$ lower chance of home death, $\mathrm{PR}=1$ indicates no association. The PRs were derived from modified Poisson regression model, adjusting for the listed variables in the main analysis but with the omission of the number of contributing CoDs, the number of CYP deaths and the number of CYP cancer deaths at SCN region level 
Table 8 Factors associated * with hospice death(versus hospital death) in children and young people with cancer, England $1993-2014(N=12,774)$

\begin{tabular}{|c|c|c|c|c|}
\hline \multirow[t]{2}{*}{ Variable } & \multirow[t]{2}{*}{ Value } & \multicolumn{3}{|l|}{ Year of death } \\
\hline & & 1993-2000 & 2001-2004 & 2005-2014 \\
\hline \multirow[t]{2}{*}{ Age(ref: 20-24) } & $0-14$ & $0.44(0.34$ to 0.58$)$ & $0.77(0.57$ to 1.05$)$ & $0.95(0.80$ to 1.12$)$ \\
\hline & $15-19$ & $0.52(0.38$ to 0.71$)$ & $0.62(0.42$ to 0.92$)$ & $0.88(0.71$ to 1.10$)$ \\
\hline Gender & Male vs female & $0.82(0.65$ to 1.03$)$ & $0.81(0.62$ to 1.07$)$ & $0.92(0.79$ to 1.07$)$ \\
\hline \multirow[t]{3}{*}{ N. contributing CoDs(ref: 0) } & 1 & $0.77(0.61$ to 0.98$)$ & $0.46(0.33$ to 0.65$)$ & $0.56(0.46$ to 0.67$)$ \\
\hline & 2 & $0.22(0.13$ to 0.37$)$ & $0.18(0.10$ to 0.33$)$ & $0.15(0.10$ to 0.23$)$ \\
\hline & $3+$ & $0.02(0.00$ to 0.17$)$ & $0.10(0.04$ to 0.24$)$ & $0.10(0.06$ to 0.17$)$ \\
\hline \multirow[t]{4}{*}{ Deprivation(ref: 5 least deprived) } & 1 (most deprived) & $1.06(0.76$ to 1.48$)$ & $0.83(0.53$ to 1.30$)$ & $0.90(0.70$ to 1.16$)$ \\
\hline & 2 & $0.92(0.64$ to 1.32$)$ & $1.07(0.69$ to 1.65$)$ & $0.85(0.66$ to 1.10$)$ \\
\hline & 3 & $0.72(0.49$ to 1.05$)$ & $1.17(0.75$ to 1.81$)$ & $1.03(0.80$ to 1.32$)$ \\
\hline & 4 & $0.77(0.52$ to 1.13$)$ & $1.03(0.65$ to 1.64$)$ & $0.90(0.69$ to 1.18$)$ \\
\hline Rural/Urban indicator & Rural vs Urban & $1.02(0.73$ to 1.45$)$ & $1.11(0.76$ to 1.64$)$ & $0.97(0.77$ to 1.22$)$ \\
\hline \multirow[t]{11}{*}{ SCN region (ref: London) } & Cheshire \& Merseyside & $2.02(1.08$ to 3.78$)$ & $1.12(0.52$ to 2.39$)$ & $0.86(0.55$ to 1.32$)$ \\
\hline & East Midlands & $1.02(0.53$ to 1.96$)$ & $0.69(0.34$ to 1.42$)$ & $0.90(0.64$ to 1.28$)$ \\
\hline & East of England & $1.55(0.86$ to 2.79$)$ & $1.59(0.93$ to 2.73$)$ & $1.23(0.90$ to 1.68$)$ \\
\hline & Greater Manchester, Lancashire and south Cumbria & $3.35(2.07$ to 5.44$)$ & $1.64(0.97$ to 2.77$)$ & $1.05(0.75$ to 1.47$)$ \\
\hline & $\begin{array}{l}\text { North East, north Cumbria, and the Hambleton } \\
\& \text { Richmondshire districts of North Yorkshire }\end{array}$ & $0.94(0.43$ to 2.04$)$ & $0.63(0.22$ to 1.81$)$ & $0.88(0.55$ to 1.42$)$ \\
\hline & South East Coast & $2.46(1.42$ to 4.26$)$ & $1.66(0.91$ to 3.03$)$ & $1.43(1.03$ to 1.99$)$ \\
\hline & South West & $2.51(1.44$ to 4.39$)$ & $1.43(0.77$ to 2.62$)$ & $1.78(1.31$ to 2.41$)$ \\
\hline & Thames Valley & $1.56(0.69$ to 3.51$)$ & $0.95(0.39$ to 2.34$)$ & $1.70(1.17$ to 2.47$)$ \\
\hline & Wessex & $1.37(0.65$ to 2.89$)$ & $0.59(0.20$ to 1.71$)$ & $0.99(0.58$ to 1.67$)$ \\
\hline & West Midlands & $2.04(1.22$ to 3.41$)$ & $0.95(0.52$ to 1.74$)$ & $1.11(0.81$ to 1.52$)$ \\
\hline & Yorkshire \& The Humber & $2.60(1.59$ to 4.27$)$ & $1.78(1.05$ to 3.00$)$ & 1.09 (0.80 to 1.48$)$ \\
\hline
\end{tabular}

*The association is measured by proportion ratios(PRs) and $95 \%$ confidence intervals. PR $>1$ indicates a higher probability of hospice death, $<1$ lower chance of hospice death, $\mathrm{PR}=1$ indicates no association. The PRs were derived from modified Poisson regression model, adjusting for the listed variables in the main analysis but with the omission of the Underlying CoD, number of CYP deaths and number of CYP cancer deaths at SCN region level. -: not estimable

\section{Acknowledgements}

The investigators of the GUIDE_Care Children and Young People project: We Gao(PI), Irene J Higginson(co-PI), Janet Peacock, Anne Greenough, Julia Verne and Myer Glickman, thank the following members of the Project Advisory Group(PAG): Tony Bonser, Dr Emma Gordon, Fiona Grove, Dr Shaheen Khan, Dr Joanna Laddie, Katie Lindsey, Dr Helen McElroy, Mrs Carolyn Morris, Mr Andy Pring. We thank Joanna Davies for her assistance with the project and data management, Clare Pearson for assisting with the shapefiles, and Dr Tara Whitburn for helping with the ICD-9/10 codes for cancer. We thank the ONS for supplying data and providing technical support in data related issues. Professor Mike Stevens at University of Bristol, Dr Martin Mccabe at University of Manchester, Dr Sujith Samarasinghe at Great Ormond Street Hospital for sharing their clinical expertise and perspectives on cancer grouping; Dr Lorna Fraser at University of York for the inspiring discussions on the preliminary results. Prof Irene J Higginson is an NIHR Senior Investigator.

The Collaboration for Leadership in Applied Health Research and Care (CLAHRC) South London is part of the National Institute for Health Research (NIHR), and is a partnership between King's Health Partners, St. George's, University London, and St George's Healthcare NHS Trust.

The National Institute for Health Research (NIHR) Biomedical Research Centre (BRC) is based at Guy's and St Thomas' NHS Foundation Trust and King's College London. This publication is independent research supported by the CLAHRC South London and the NIHR BRC. The views expressed in this publication are those of the author(s) and not necessarily those of the NHS, the National Institute for Health Research or the Department of Health.

\section{Funding}

This work is part of the GUIDE_Care Children and Young People project - funded by Marie Curie Cancer Care - A15822.

\section{Availability of data and materials}

According to the data agreement we signed with the Office for National Statistics (ONS), we are not allowed to share our data. The access to the data would need special approvals from the ONS

\section{Authors' contributions}

The authors made a substantial contribution to: the conception and design of the study: WG, IJH, JP, AG, JV; the organisation of conduct of the study: WG, IJH, $\mathrm{JV}$; carrying out the study(including acquisition of study data): WG, IJH, JV, CW, CS. the development of analysis plan: all authors. the data analysis: WG. to the interpretation of study data: all authors. WG wrote the first draft of the paper with significant inputs from $\mathrm{IJH}$; all authors commented on, contributed to the final draft and agreed with manuscript results and conclusions; all authors read and meet ICMJE criteria for authorship; WG and IJH are the co-guarantors. WG and $\mathrm{IJH}$ affirm that the manuscript is an honest, accurate, and transparent account of the study being reported; that no important aspects of the study have been omitted; and that any discrepancies from the study as planned have been explained. All authors have read and approved the manuscript.

\section{Competing interests}

The authors declare that they have no competing interests. 


\section{Consent for publication}

Not applicable.

\section{Ethics approval and consent to participate}

This study was based on fully anonymised records therefore no ethical approval was required according to the Information Commissioner's Office (ICO) guidelines, ONS procedures, and those of the King's College London Research Ethics Committee.

\section{Author details}

'King's College London, Cicely Saunders Institute, Department of Palliative Care, Policy and Rehabilitation, Bessemer Road, Denmark Hill, London SE5 9PJ, UK. ${ }^{2}$ Public Health England, Knowledge \& Intelligence Team (South West), Grosvenor House, 149 Whiteladies Road, Bristol BS8 2RA, UK. ${ }^{3}$ King's College London, Division of Health and Social Care Research, Addison House, Guy's Campus, London SE1 1UL, UK. ${ }^{4}$ Public Health England, Childhood Cancer, 4150 Chancellor Court, Oxford Business Park South, Oxford OX4 2GX, UK. ${ }^{5}$ Office for National Statistics, Life Events and Population Sources Division, Cardiff Road, Newport, Wales NP10 8XG, UK. 'King's College London, School of Medicine, Division of Asthma, Allergy and Lung Biology, Denmark Hill, London SE5 9RS, UK

Received: 3 April 2016 Accepted: 7 August 2016

\section{Published online: 19 September 2016}

\section{References}

1. Department of Health. End of life care strategy: promoting high quality care for all adults at the end of life. 2008. p. 171.

2. Waghorn M, Young H, Davies A. Opinions of patients with cancer on the relative importance of place of death in the context of a 'good death'. BMJ Support Palliat Care. 2011;1(3):310-4.

3. Ito Y, Okuyama T, Ito Y, Kamei M, Nakaguchi T, Sugano K, Kubota Y, Sakamoto N, Saitoh S, Akechi T. Good death for children with cancer: a qualitative study. Jpn J Clin Oncol. 2015;45(4):349-55.

4. Grinyer A, Thomas C. The importance of place of death in young adults with terminal cancer. Mortality. 2004;9(2):114-31.

5. Ruegger J, Hodgkinson S, Field-Smith A, Ahmedzai SH. Care of adults in the last days of life: summary of NICE guidance. Bmj. 2015;35:h6631.

6. Gao W. Changing Patterns in Place of Cancer Deaths in England, 2001-2010: Time Trends and Associated factors In: Society for Social Medicine (Oral Presentation) 56th Annual Scientific Meeting: 2012. London: PloS Med; 2012.

7. Sleeman KE, Ho YK, Verne J, Gao W, Higginson IJ, project GUC. Reversal of english trend towards hospital death in dementia: a population-based study of place of death and associated individual and regional factors, 2001-2010. BMC Neurol. 2014;14:59.

8. Evans CJ, Ho Y, Daveson BA, Hall S, Higginson IJ, Gao W. Project GC: place and cause of death in centenarians: a population-based observational study in England, 2001 to 2010. PLoS Med. 2014:11(6):e1001653.

9. Howell D, Wang H-I, Smith A, Howard M, Patmore R, Roman E. Place of death in haematological malignancy: variations by disease sub-type and time from diagnosis to death. BMC Palliative Care. 2013;12(1):42.

10. Hedinger D, Braun J, Zellweger U, Kaplan V, Bopp M, Swiss National Cohort Study G. Moving to and dying in a nursing home depends not only on health - an analysis of socio-demographic determinants of place of death in Switzerland. PloS one. 2014;9(11):e113236.

11. What is the Preferred Priorities of Care (PPC) document? [http://www. cancerresearchuk.org/about-cancer/cancers-in-general/cancer-questions/ preferred-priorities-for-care]

12. INDEPENDENT REVIEW OF THE LIVERPOOL CARE PATHWAY, NEUBERGER Julia. Department of Health. More care, less pathway: a review of the Liverpool care pathway. Great Britain: Department of Health: 2013. p. 63.

13. Henry C, Fenner P. An introduction to the NHS End of life care programme. End of Life Care. 2007;1(1):5.

14. Widdas D., McNamara K., Edwards F. A Core Care Pathway for Children with Life-limiting and Life-threatening Conditions In. Edited by Susannah Woodhead, Third edn. Bristol; Together for short lives: 2013. p. 44.

15. Department of Health. Better care, better lives: improving outcomes and experiences for children, young people and their families living with life-limiting and life-threatening conditions. 2008. p. 55.

16. Carter YH, Petchey R, Williams J. Evaluation of the New opportunities fund palliative care initiative: first annual report. 2004.
17. Gao W, Ho YK, Verne J, Glickman M, Higginson IJ, project GUC. Changing patterns in place of cancer death in England: a population-based study. PLoS Med. 2013;10(3):e1001410.

18. Teno JM, Gozalo PL, Bynum JP, Leland NE, Miller SC, Morden NE, Scupp T, Goodman DC, Mor V. Change in end-of-life care for medicare beneficiaries: site of death, place of care, and health care transitions in 2000, 2005, and 2009. JAMA. 2013;309(5):470-7.

19. Miller EG, Levy C, Linebarger JS, Klick JC, Carter BS. Pediatric palliative care: current evidence and evidence gaps. J Pediatr. 2015;166(6):1536-1540.e1531.

20. Fraser LK, Miller M, Hain R, Norman P, Aldridge J, McKinney PA, Parslow RC. Rising national prevalence of life-limiting conditions in children in England. Pediatrics. 2012;129(4):e923-9.

21. Devanney C, Bardley S. Together for short lives: count me in: Children's hospice service provision 2011/12. Durham: Durham University School of Applied Social Sciences; 2012. p. 45.

22. Higginson IJ, Thompson M. Children and young people who die from cancer: epidemiology and place of death in England (1995-9). BMJ. 2003;327(7413):478-9.

23. Shah A, Diggens N, Stiller C, Murphy D, Passmore J, Murphy MF. Place of death and hospital care for children who died of cancer in England, 1999-2006. Eur J Cancer. 2011;47(14):2175-81.

24. Leading Causes of Death Reports, National and Regional, 1999 - 2013 [http://webappa.cdc.gov/sasweb/ncipc/leadcaus10_us.html]

25. Viner RM, Hargreaves DS, Coffey C, Patton GC, Wolfe I. Deaths in young people aged 0-24 years in the UK compared with the EU15+ countries, 1970-2008: analysis of the WHO mortality database. Lancet. 2014;384(9946):880-92.

26. Cancer mortality by age [http://www.cancerresearchuk.org/cancer-info/ cancerstats/mortality/age/uk-cancer-mortality-statistics-by-age]

27. NHS Commissioning Board; NC. The way forward: clinical senates. 2013.

28. Galobardes B, Shaw M, Lawlor DA, Lynch JW. Indicators of socioeconomic position (part 1). J Epidemiol Community Health. 2006;60(1):7-12.

29. Schlomer GL, Bauman S, Card NA. Best practices for missing data management in counseling psychology. J Couns Psychol. 2010;57(1):1-10.

30. National Collaborating Centre for Cancer. Improving outcomes in children and young people with cancer. London: National Institute for Health and Clinical Excellence (NICE); 2005.

31. Vickers J, Thompson A, Collins GS, Childs M, Hain R. Place and provision of palliative care for children with progressive cancer: a study by the paediatric oncology Nurses' forum/United Kingdom children's cancer study group palliative care working group. J Clin Oncol. 2007;25(28):4472-6.

32. Tzuh Tang S, Hung YN, Liu TW, Lin DT, Chen YC, Wu SC, Hsia Hsu T. Pediatric end-of-life care for Taiwanese children who died as a result of cancer from 2001 through 2006. J Clin Oncol. 2011;29(7):890-4.

33. Mack JW, Chen LH, Cannavale K, Sattayapiwat O, Cooper RM, Chao CR. End-of-life care intensity among adolescent and young adult patients with cancer in kaiser permanente southern California. JAMA oncology. 2015:1(5):592-600

34. Feudtner C, Feinstein JA, Satchell M, Zhao H, Kang TI. Shifting place of death among children with complex chronic conditions in the United States, 1989-2003. JAMA. 2007;297(24):2725-32.

35. Wilson DM, Hewitt JA, Thomas RE, Woytowich B. Why did an out-of-hospital shift of death and dying occur in Canada after 1994? Int J Palliat Care. 2014;2014:11.

36. McNamara B, Rosenwax L. Factors affecting place of death in Western Australia. Health \& Place. 2007;13(2):356-67.

37. Howell D, Roman E, Cox H, Smith A, Patmore R, Garry A, Howard M. Destined to die in hospital? systematic review and meta-analysis of place of death in haematological malignancy. BMC Palliative Care. 2010;9(1):9.

38. McPherson D, Griffiths C, Williams M, Baker A, Klodawski E, Jacobson B, Donaldson L: Sepsis-associated mortality in England: an analysis of multiple cause of death data from 2001 to 2010. BMJ Open. 2013; 3(8):e002586.

39. Rockett IR, Lian Y, Stack S, Ducatman AM, Wang S. Discrepant comorbidity between minority and white suicides: a national multiple cause-of-death analysis. BMC Psychiatry. 2009;9:10.

40. Stevenson J, Abernethy AP, Miller C, Currow DC. Managing comorbidities in patients at the end of life. BMJ. 2004;329(7471):909-12.

41. ONS. Childhood cancer survival in England, children diagnosed from 1990 to 2008 and followed up to 2013. In: Statistical bulletin. London: ONS; 2015. p. 10 
42. American Academy Of Pediatrics. Long-term follow-up care for pediatric cancer survivors. Pediatrics. 2009;123(3):906-915.

43. Viner RM, Coffey C, Mathers C, Bloem P, Costello A, Santelli J, Patton GC. 50-year mortality trends in children and young people: a study of 50 low-income, middle-income, and high-income countries. The Lancet. 2011;377(9772):1162-1174.

44. Bray F, Jemal A, Grey N, Ferlay J, Forman D: Global cancer transitions according to the Human Development Index (2008\&\#x2013;2030): a population-based study. The Lancet Oncology. 2012;13(8): 790-801.

45. Dixon J, King D, Matosevic T, Clark M, Knapp M: Equity in the Provision of Palliative Care in the UK: Review of Evidence. In.: Personal Social Services Research Unit, London School of Economics and Political Science; London. 2015. p. 148

46. Lien Foundation. The 2015 quality of death index ranking palliative care across the world: a report by the economist intelligence unit. 2015. p. 1-71.

47. Thomas C, Morris SM, Clark D. Place of death: preferences among cancer patients and their carers. Soc Sci Med. 2004;58(12):2431-44.

Submit your next manuscript to BioMed Central and we will help you at every step:

- We accept pre-submission inquiries

- Our selector tool helps you to find the most relevant journal

- We provide round the clock customer support

- Convenient online submission

- Thorough peer review

- Inclusion in PubMed and all major indexing services

- Maximum visibility for your research

Submit your manuscript at www.biomedcentral.com/submit 